\title{
REFLECTING ON EFFICACY OF MEANINGS INTO WORDS INTERMEDIATE
}

\author{
Kedar Prasad Sah \\ Department of English Education
}

\begin{abstract}
The present paper is an attempt to share some reflections on the effectiveness of the textbook 'Meanings into Words Intermediate' prescribed by Higher Secondary Education Board for the students of grade XI. This largely draws on my experience of teaching the course for more than a decade.
\end{abstract}

\section{Keywords}

Communicative approach, notional-functional syllabus, controlled practice, free practice, Presentation-Practice-Production (PPP)

\section{Introduction}

Meanings into Words Intermediate is one of the three textbooks prescribed for compulsory English for grade 11 students of Higher Secondary Education Board (HSEB), others being Magic of Words and Link English. The weighting of the book covers 50 percent of the total 100 marks of the final examination. It is an integrated course in General English. To be specific, it is a course in grammar and its use in communication. It sets out to teach the grammatical system of English in relation to the uses to which the learner will predictably want to put it. As its name indicates, grammar of English has been presented as a means for putting into words many of the meanings the learner will want to express in the process of using language for various communicative purposes. It also aims to develop an understanding and command of grammar in terms of form, meaning and use.

This in fact integrates both traditional and communicative approaches to language teaching. The book synthesizes both structural and functional contents together. This is because structural courses tend to teach form and meaning, but not use which is covered by functional syllabus (Doff, Jones and Mitchell, 1997). The book contains 24 units altogether. Based on functional-notional syllabus, each unit of the book contains: presentation material which introduces key language items, intensive controlled practice, freer communicative practices, writing 


\section{K. P. Sah}

activities, listening and reading passages, and language summary at the end. Presentation techniques in the textbook are designed to suit the requirements of the language being taught, and to involve students as much as possible. There is a wide variety of presentation material: language may be presented by reading, by listening or by written examples and the presentation often involves interpretation and class discussion. The practice stage is concerned with controlled practice of new language. It ranges from simple manipulation of structures to more imaginative practice in which students use language in realistic situations. Practice is usually done in pairs or small groups and is concerned with appropriate use of language as well as with accuracy. At this stage, students are not limited to using particular language. Practice may take the form of role play, group discussion or students talking about themselves and gives them a chance to practice the language they have learnt in a wider context. Practice in writing is provided at any stage of the unit where it is appropriate. It usually takes the form of paragraph writing, either based on classroom discussion or as a follow up to listening or reading comprehension. Each unit ends with a reading or a listening passage which features the language of the unit. These passages are followed by comprehension questions, but may also be used as a basis for note taking, writing, discussion, or role-play. From Unit 4 onwards, each unit has an Activities page and it contains some activities that combine and recycle language learnt in earlier units. At the end of the every unit, there is ample scope for strengthening writing skills because compositions related to different areas are provided. Students can share their experiences, or narrate the situations in real life such as festivals, cultural occasions, places etc.

Meanings into Words Intermediate covers seven functional areas of language: Action, Description, Personal Information, Narration, Pastand Present, Comparisonand Explanation. The area of action consists of language used for talking about the desirability and possibility of actions: initiating action in oneself and commenting on one's s own actions and the actions of other people. Description consists of language used for physical description of places, things and people: their appearance, their features and their location. The area of personal information consists of language used for giving information about students themselves, and other people: who you are, what you are, what you do, and what kind of person you are. The area of Past and Present consists of language used for relating the past and the present: present situations and their past origins, past events and their connection with the present actions and activities during the period up to now. Similarly, the area of comparison consists of language used for comparing and evaluation: talking about similarities and differences, measuring differences, and assessing advantages and disadvantages. Finally, the area of explanation consists of language used for explaining things and speculating about them. This includes saying why and how things happen, establishing the truth about things, and drawing conclusions about the past, present and future. Each of the seven areas is categorized into a number of units, which are arranged in such a way as to provide a natural and logical progression, an increasing level of difficulty throughout the textbook, maximum variety and motivation for the student.

\section{Reflections on the textbook}

I have been involved in teaching Meaning into Words Intermedaite and Upper Intermediate for the last ten years and my reflections on the textbook can be summed in the following paragraphs:

The course book written by foreign authors alienate the students. There are many foreign words and phrases such as sun tan, caviar, making love etc, description of foreign places such as streets of London, texts on western festivals which are removed from local cultures and realities. They merely westernize our learners and make them forget our own cultural heritages. Pathank states "The names of people, places, customs and traditions etc. 
are all western which makes it difficult for our learners, especially from rural background who hear and know mostly of their immediate surroundings only, due to difficulties of information transfer to such areas"(,2004).

Likewise, Kansakar( 1999, p.6) maintains that "we are taking for granted that Nepalese students will easily comprehend and assimilate materials based solely on western arts and letters, philosophy and culture. We need to abandon the common fallacy that western literature represents best use of English and that our teaching materials should therefore be based on western-oriented texts"(cited in K.C.,2003).

The book follows structuralism/ audiolingualism which suggests teaching language through Presentation-Practice Production (PPP) model. The PPP model of language teaching is more teacher-centered, focuses on pattern practice and therefore has little space for creativity of the students. It is very unfortunate that while we are aware that language is characterized by creativity (productivity), we keep on following blindly those trends that support memorization, practice and repetition etc.

HSEB has been still following the book which does not reflect the current paradigm in ELT in any way. ELT around the globe has changed considerably. Recently, context sensitive approach has been advocated and it is very necessary that the book gets replaced.

Students are found to have little interest in notions that are distant and do not have connection with the real life situations. The notions presented in the textbook are western and therefore little familiar with the teachers, and let alone the students. Students are hardly motivated to the contexts and concepts given in the book.

\section{Conclusion}

Language teaching has moved from audiolingualism to communicative language teaching and very recently people have been advocating post method approach which is context sensitive. Therefore, it is high time HSEB dismissed this old fashioned textbook and replace it by modern ones which are based recent paradigm shifts in ELT. It is responsibility of HSEB to encourage and involve Nepalese ELT experts cum authors in the preparation of the textbook in accordance with Nepalese cultures and values.

\section{References}

Doff A., Jones, C., \& Mitchell, K. (1997). Meanings into words intermediate. Cambridge: CUP.

Doff A., Jones, C., \& Mitchell, K. (1997). Meanings into words intermediate Teacher's book. Cambridge: CUP.

K.C. K. B. (2003). Critical analysis and evaluation of the exisitng compulsory English syllabus of higher secondary level. Journal of NELTA, 8, 142-148.

Pathank, L. S. (2004). Sun tan oil? Caviar? $\mathrm{Au}$ Pair Girl?: Some of the notions in intermediate English(Meanings into Words) we could do without. Journal of NELTA, 9, 41-48.

\section{The Author}

Kedar Prasad Sah is an Associate Professor in English Education, Thakur Ram Multiple Campus, Birgunj. Having been associated with English Language Teaching for more almost decades, Sah teaches courses such as English Literature and Language Testing and Translation Studies. Currently, he heads Nepal English Language Teachers' Association (NELTA), Birgunj Chapter. To his credit, he has published articles in ELT Today, a journal of NELTA Birgunj.

Email: kp_sah@yahoo.com 